\title{
AVALIAÇÃO DE UM CONSÓRCIO MICROBIANO ENRIQUECIDO A PARTIR DE ÁGUA DE PRODUÇÃO DE UM RESERVATÓRIO DE ÓLEO OFF SHORE EM RELAÇÃO AO USO DO ACETATO E DO PROPIONATO PARA A PRODUÇÃO DE SULFETO
}

\author{
W. A. CAMACHO ${ }^{1}$, C. R. BRESSAN ${ }^{1}$, W. SCHMIDELL ${ }^{1}$, A. FURIGO JUNIOR ${ }^{1}$, H. X. \\ CORSEUIL $^{2}$, F. DE A. ODAGUIRI ${ }^{1}$, F. SPINA ${ }^{1}$ e H. M. SOARES ${ }^{1}$ \\ ${ }^{1}$ Universidade Federal de Santa Catarina, Departamento de Engenharia Química e Engenharia \\ de Alimentos \\ ${ }^{2}$ Universidade Federal de Santa Catarina, Departamento de Engenharia de Sanitária e \\ Ambiental \\ E-mail para contato: walca88@hotmail.com
}

\begin{abstract}
RESUMO - Um dos maiores problemas nos poços de petróleo é a presença de acidez biogênica (souring) gerada pela produção de sulfeto. $\mathrm{O}$ controle do souring em reservatórios pode ser feito através da injeção de nitrato, o que provoca a inibição da redução de sulfato pelas Bactérias Redutoras de Sulfato (BRS). O estudo feito avalia a capacidade de um consórcio microbiano, enriquecido a partir de água de produção de um reservatório de óleo off shore, em relação ao uso do acetato e do propionato como fonte de matéria orgânica para a produção de sulfeto pelas BRS. Essa avaliação foi realizada a fim de subsidiar a elaboração de futuros ensaios para estudo de processos biotecnológicos para inibição das BRS. Foram testadas três condições distintas em relação ao doador de elétrons disponível: acetato, propionato e acetato + propionato. Os frascos foram incubados em uma incubadora com agitação orbital por 20 horas, sendo que as amostras foram coletadas a cada 2 horas para a análise de sulfeto. Os resultados sugerem que o consórcio de bactérias estudado tem uma preferência pelo propionato quando ambos os substratos estão disponíveis.
\end{abstract}

\section{INTRODUÇÃO}

A corrosão, processo químico ou eletroquímico que deteriora ligas metálicas, levando o metal para uma forma menos energética (Schweitzer, 2010), é um dos principais problemas que atinge as ligas metálicas utilizadas na indústria petroleira, onerando o orçamento das mesmas com altos custos empregados em manutenção (Zarasvand, Rai R 2014).

Nos poços de petróleo, bactérias atuam como protagonistas do fenômeno da corrosão influenciada por microrganismos (MIC). Esse processo é conhecido como acidificação biogênica (souring). Uma das principais bactérias causadoras da acidez biogênica são as bactérias redutoras de sulfato (BRS) (Enning et al, 2012). As BRS utilizam comumente como doador de elétrons compostos orgânicos e como aceptor de elétrons sulfato, disponível em grande quantidade na água do mar que é injetada. O sulfato introduzido nos poços é convertido em produto na forma de íon sulfeto. (Hubert e Voordouw, 2007). 
As BRS compreendem um diversificado grupo e apresentam um papel central no ciclo do carbono em condições anaeróbicas nos oceanos. São capazes de crescer a partir de ácidos graxos de cadeia curta, incluindo acetato e propionato, ou em ácidos graxos de cadeia longa e compostos aromáticos (Widdel, 1980). Além disso, também são capazes de crescer na presença do óleo bruto como a única fonte de carbono (Wilkes, 2000). Em relação à sua capacidade de metabolização do carbono orgânico, as BRS podem ser divididas em dois grupos: os que degradam compostos orgânicos de forma incompleta até acetato e aqueles que degradam compostos orgânicos de forma completa ate dióxido de carbono. (Muyzer e Stams, 2008).

O presente artigo avalia o consumo do acetato e propionato por um consórcio microbiano enriquecido a partir de água de produção que contem BRS. Foram escolhidos esses compostos por serem provavelmente os substratos mais facilmente biodegradados dentre os compostos disponíveis para as BRS nos poços de petróleo.

\section{MATERIAIS E MÉTODOS}

\subsection{Condições experimentais}

A biomassa para o ensaio foi coletada de dois reatores de manutenção de inóculo que foram inoculados com água de produção de poços de petróleo e que vem sendo mantidos por mais de cinco anos com alimentação idêntica de acetato, propionato e nitrato para enriquecimento e manutenção do consórcio de bactérias. Tomou-se um litro de cada reator que foi mantido por 10 minutos com injeção de argônio com o objetivo de manter a biomassa em anaerobiose e reduzir a concentração de sulfeto proveniente dos reatores. Após este procedimento, foram medidas as concentrações de sólidos suspensos voláteis (SSV) e fixos (SSF), ficando a concentração de biomassa para o ensaio cinético em 1,37 g SSV.L ${ }^{-1}$. Para o preparo do substrato foram testadas três condições em relação ao doador de elétrons disponível: acetato (200 mg. $\left.\mathrm{L}^{-1}\right)$; propionato $\left(160 \mathrm{mg} \cdot \mathrm{L}^{-1}\right)$; e acetato $\left(200 \mathrm{mg} . \mathrm{L}^{-1}\right)$ + propionato $\left(160 \mathrm{mg} . \mathrm{L}^{-1}\right)$. Como no preparo de inoculo utilizou-se borbulhamento com argônio para remoção do sulfeto, a biomassa utilizada no ensaio cinético apresentava uma pequena quantidade de acetato residual.

Os experimentos foram realizados utilizando a estratégia de frascos de sacrifício com volume útil de $50 \mathrm{~mL}$. Foram incubados em agitador orbital a $27^{\circ} \mathrm{C}$ e agitação de $200 \mathrm{rpm}$. O ensaio teve duração total de 20 horas, sendo que as amostras eram coletadas a cada 2 horas para a análise de sulfeto e dos íons acetato e propionato.

\subsection{Metodologia analítica}

Determinação da série de sólidos - Sólidos Suspensos Totais (SST), Sólidos Suspensos Fixos (SSF) e Sólidos Suspensos Voláteis (SSV): A concentração de biomassa foi estimada através da determinação da concentração de SSV (sólidos suspensos voláteis) (APHA, AWWA e WEF, 1995), com modificação do protocolo originalmente descrito pela utilização de forno microondas para secagem das amostras (ZDRADEK, 2005). A técnica utilizada consiste em filtração das amostras em membrana de acetato de celulose com poro de $0,22 \mu \mathrm{m}$ de diâmetro, seguida de secagem em microondas (15 min com 20\% de potência) para determinação da concentração de SST (sólidos suspensos totais). Após isso, as amostras foram calcinadas em mufla $\left(550^{\circ} \mathrm{C}-1\right.$ hora) para queima da fração orgânica da amostra, 
permitindo a determinação da concentração de SSF (sólidos suspensos fixos). A concentração de SSV é então estimada pela diferença entre a concentração de SST e SSF encontrada.

Cromatografia de íons: Para as análises dos íons foi utilizado um cromatógrafo de íons ICS 5000 (Dionex) equipado com dois sistemas cromatográficos em paralelo para detecção amperométrica e condutivimétrica, sendo o último sistema equipado com gerador de eluente $\mathrm{KOH}$ e supressora eletrolítica.

As análises de acetato e propionato foram realizadas utilizando-se detecção condutivimétrica com supressão eletrolítica. Para separação dos ânions utilizou-se coluna capilar IonPac AS18-Fast $(0,4$ x $150 \mathrm{~mm})$ e pré-coluna IonPac AG18-Fast $(0,4$ x $35 \mathrm{~mm})$, ambas da marca Dionex, com volume de injeção de $0,4 \mu \mathrm{L}$ e vazão de eluente de 0,012 ml.min-1. Utilizou-se temperatura de $30{ }^{\circ} \mathrm{C}$ e $35^{\circ} \mathrm{C}$ na coluna e detector, respectivamente.

Para a determinação da concentração de sulfeto foi também utilizada cromatografia iônica, porém, utilizando-se detecção amperométrica. Neste caso foi utilizado como eluente uma solução composta de acetado de sódio $(400 \mathrm{mM})$ e hidróxido de sódio $(200 \mathrm{mM})$ à vazão de eluente de $0,4 \mathrm{~mL} \cdot \mathrm{min}^{-1}$. O volume injetado foi de $10 \mu \mathrm{L}$ e para separação dos íons empregou-se uma coluna do tipo IonPac AS7 $(2 \times 250 \mathrm{~mm})$ e pré-coluna IonPac AG7 $(2$ x 50 $\mathrm{mm})$, ambas da marca Dionex. A temperatura da coluna foi de $40^{\circ} \mathrm{C}$. Para as análises de acetato e propionato as mostras foram diluídas 200 vezes para redução da interferência do cloreto na determinação dos demais íons; e para as análises de sulfeto 200 vezes em função da alta sensibilidade do método.

\section{RESULTADOS E DISCUSSÃO}

A Figura mostra as concentrações de sulfeto ao longo do ensaio. Pode-se observar velocidades de produção de sulfeto semelhantes até a $10 .^{a}$ hora de cultivo, sugerindo inicialmente uma boa versatilidade da biomassa em relação à utilização destes dois compostos para a redução do sulfato. Depois desse período, a concentração de sulfeto na condição em que havia apenas acetato estabilizou-se enquanto que os ensaios com a mistura de acetato + propionato e o ensaio apenas com propionato estabilizaram-se em 14 horas e 17 horas, respectivamente. As concentrações finais de sulfeto produzido foram crescentes na mesma ordem da estabilização.

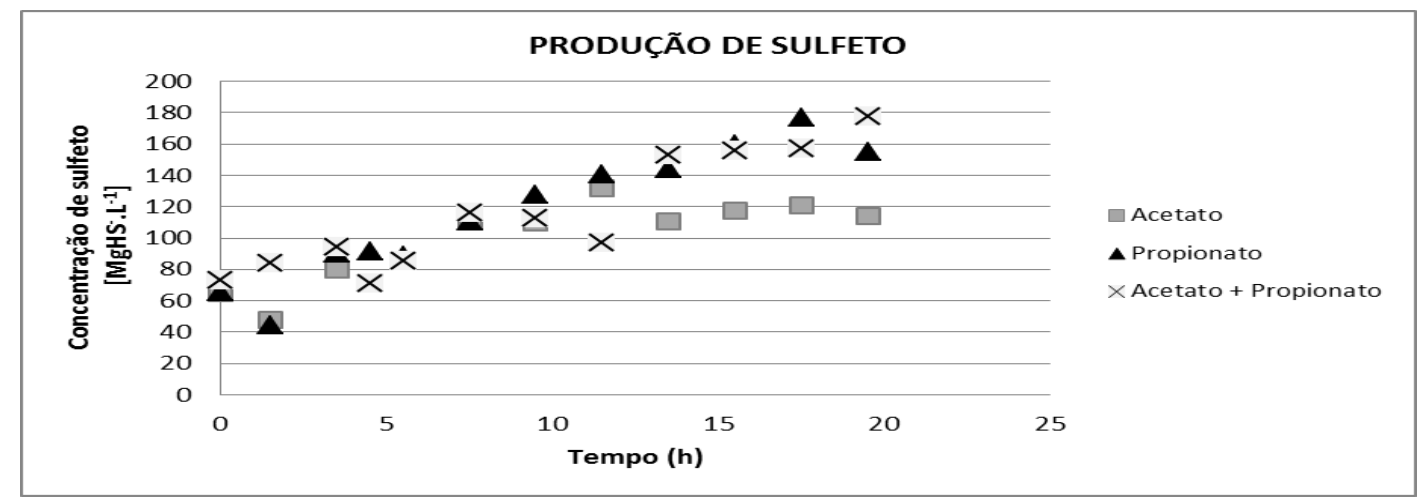

Figura 1 - Perfis da concentração de sulfeto durante ensaios cinéticos com diferentes fontes de carbono. 
Os dados obtidos a partir das análises de consumo de acetato e propionato dos ensaios realizados encontram-se nas Figura 2, Figura 3, Figura 4. Observando-se as velocidades de consumo destes compostos, obtidas a partir da linearização dos dados apresentados nestas figuras, observa-se que o consumo do propionato é preferencial em relação ao acetato. Quando apenas o acetato foi fornecido como fonte de matéria orgânica Figura 2, a velocidade de consumo do mesmo foi de $1,6 \mathrm{mg} \cdot \mathrm{L}^{-1} \cdot \mathrm{h}^{-1}$.

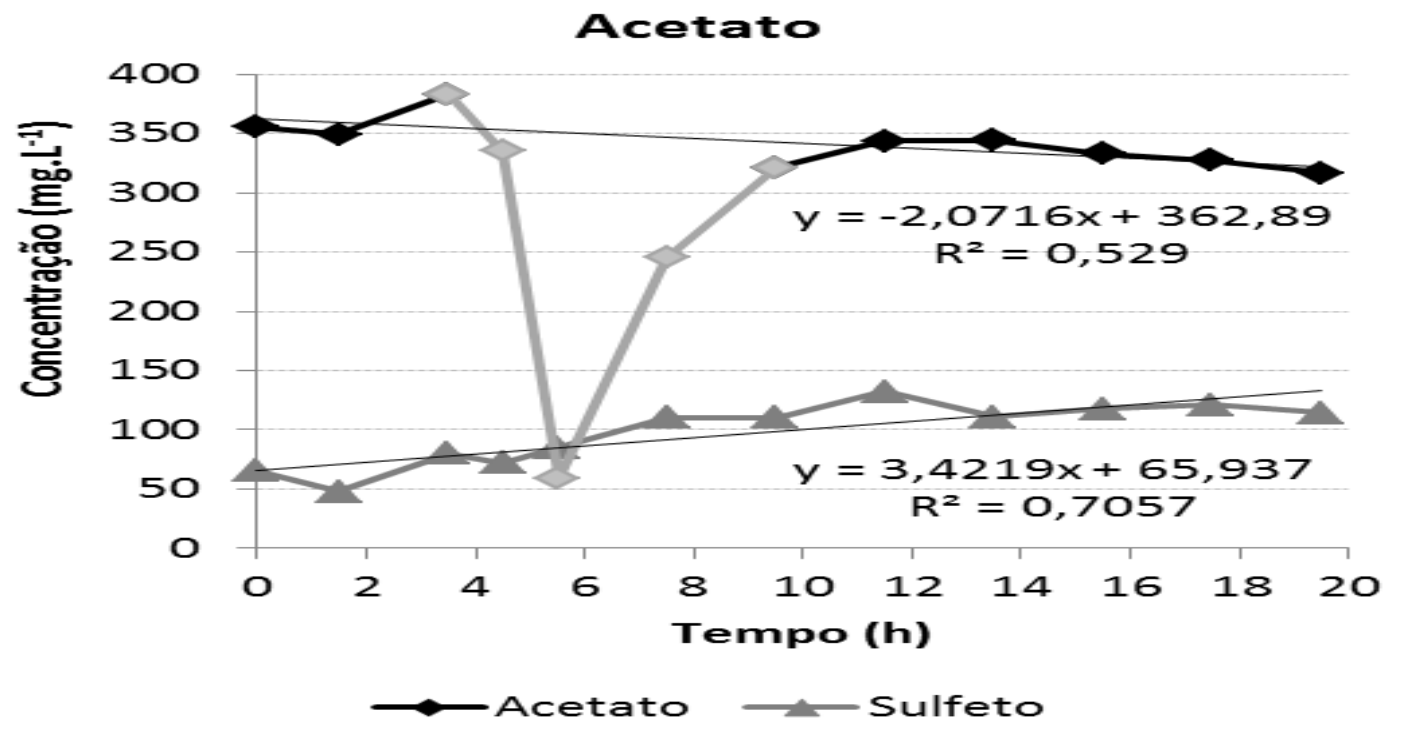

Figura 2 - Perfis das concentrações de propionato, acetato e sulfeto condição com acetato

Já na condição onde apenas propionato foi adicionado Figura 3, a velocidade de consumo do propionato se elevou para $2,3 \mathrm{mg} \cdot \mathrm{L}^{-1} \cdot \mathrm{h}^{-1}$. Vale ressaltar que no ensaio de degradação do propionato havia a presença de um residual de $50 \mathrm{mg} . \mathrm{L}^{-1}$ de acetato proveniente do meio de cultura; mesmo assim não teve consumo ou acumulo de acetato dado que todo o acetato produzido do propionato foi consumido.

\section{Propionato}

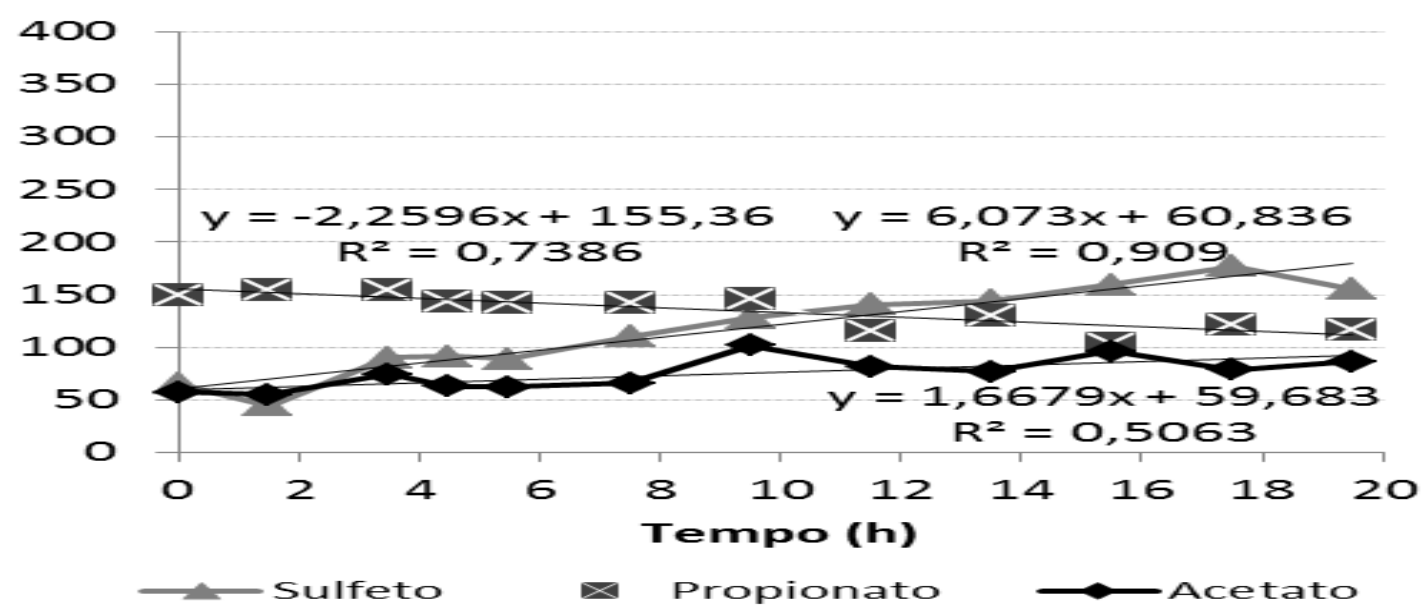

Figura 3 - Perfis das concentrações de propionato, acetato e sulfeto condição com propionato. 
$\mathrm{Na}$ condição em que a mesma quantidade de acetato foi fornecida juntamente com o propionato Figura 4, observa-se uma concentração praticamente constante de acetato ao longo do ensaio, o que indicaria que a velocidade de consumo do acetato seria equivalente à de produção a partir do propionato, uma vez que o propionato é convertido inicialmente a acetato nesse processo. Considerando uma velocidade de consumo do propionato de $1,4 \mathrm{mg} \cdot \mathrm{L}^{-1} \cdot \mathrm{h}^{-1}$, pode-se estimar que esta velocidade de produção, e, portanto, de consumo do acetato seria de $1,1 \mathrm{mg} \cdot \mathrm{L}^{-1} \cdot \mathrm{h}^{-1}$.

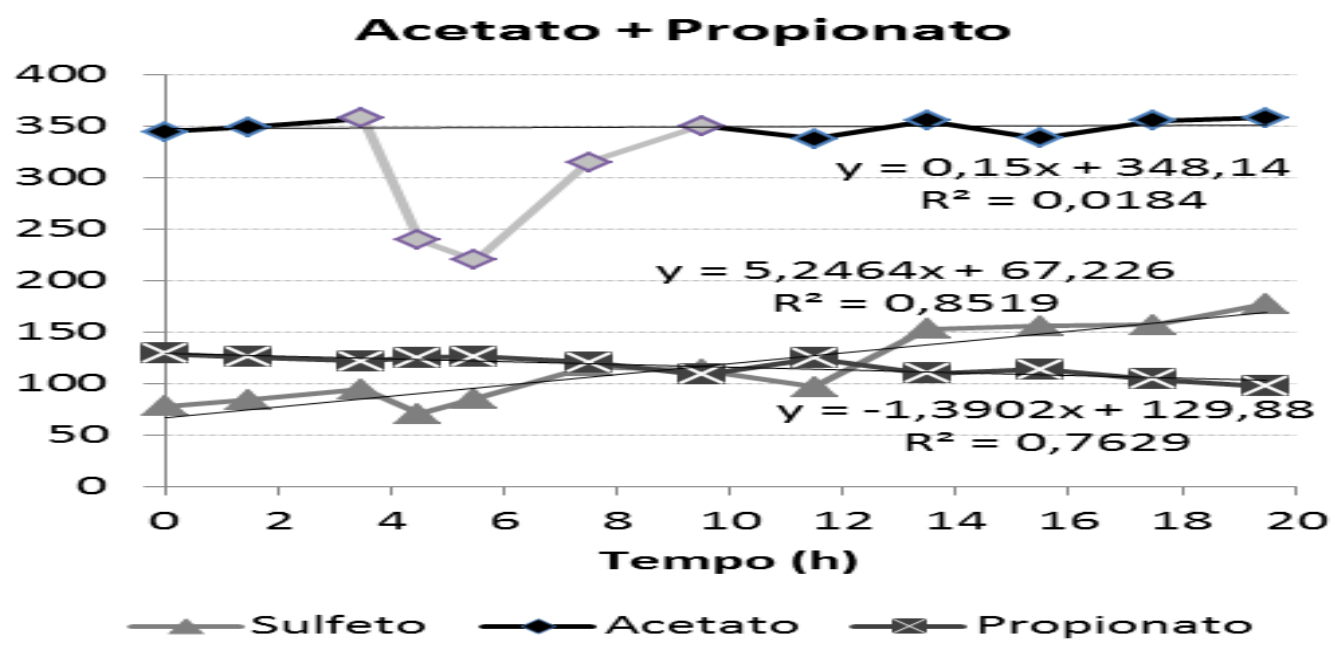

Figura 3- Perfis das concentrações de propionato, acetato e sulfeto condição com acetato + propionato

Observou-se também uma depleção temporária do acetato nas condições onde o mesmo fora adicionado, sendo parcialmente removido e reposto no meio reacional durante as primeiras $10 \mathrm{~h}$ do experimento. Para o cálculo da velocidade de consumo do acetato este período foi desconsiderado.

Com base nas equações de estequiometria teóricas para a redução do sulfato desenvolvidas conforme procedimento descrito por Rittman \& McCarty (2001), espera-se uma produção máxima de $0,51 \mathrm{mg} \mathrm{HS} \cdot \mathrm{mg}^{-1}$ acetato e $0,72 \mathrm{mg} \mathrm{HS} \cdot \mathrm{mg}^{-1}$ propionato. Os valores de produção de sulfeto obtidos nos ensaios cinéticos, todavia, são superiores ao esperado com base no consumo de matéria orgânica observado. Esta produção de sulfeto excedente não pôde ser explicada com base apenas nas variáveis avaliadas.

\section{CONCLUSÕES}

Observou-se nos ensaios para verificação da cinética de consumo de acetato e propionato pelas BRS uma produção maior de sulfeto nos ensaios que tinham uma presença de propionato comparativamente ao acetato, que sugere que este substrato é preferencialmente utilizado pelas BRS para a produção de sulfeto. 


\section{AGRADECIMENTOS}

Petrobrás,

Universidade federal de santa Catarina e

CNPq.

\section{REFERENCIAS}

APHA; AWWA; WEF. Standard methods for the examination of water and wastewater. 19ed. Washington, DC.: American Public Health Association, 1995.

HUBERT, C., VOORDOUW, G. Oil field souring control by nitrate-reducing SulFurospirillum spp. Applied and Environmental Microbiology v 73, p 2644-2652, 2007.

MUYZER, G.; STAMS, A. J. M. The ecology and biotechnology of sulphate-reducing bacteria. Nature Reviews - Microbiology, v. 6, p 441-454 2008.

RITTMANN, B. E.; MCCARTY, P. L. Environmental Biotechnology: Principles and Applications. McGraw-Hill, 2001.

WILKES, H. Anaerobic degradation and carbon isotopic fractionation of alkylbenzenes in crude oil by sulphate - reducing bacteria. Organic Geochemistry v 31, p 101-115, 2000.

ZARASVAND K, ; RAI R. Microorganisms: Induction and inhibition of corrosion in metals. International Biodeterioration \& Biodegradation v. 87, p 66-74. 2014.

ZDRADEK, C. P. Seleção de linhagens oxidadoras de amônio e remoção de nitrogênio via nitrito em reator descontínuo alimentado (SBR), sob condições de limitação de oxigênio. Teses Doutorado UFSC, 2005. 